\title{
Prematurity Is Related to High Placental Cortisol in Preeclampsia
}

\author{
MYRIAM AUFDENBLATTEN, MARC BAUMANN, LUIGI RAIO, BERNHARD DICK, BRIGITTE M. FREY, \\ HENNING SCHNEIDER, DANIEL SURBEK, BERTHOLD HOCHER, AND MARKUS G. MOHAUPT
}

\begin{abstract}
Department of Nephrology and Hypertension [M.A., B.D., B.M.F., B.H., M.G.M.], Department of Obstetrics and Gynecology [M.B., L.R., H.S., D.S.], University of Bern, 3010 Berne, Switzerland; Center for Cardiovascular Research/Institute of Pharmacology [B.H.], Charité, 10115 Berlin, Germany
\end{abstract}

\begin{abstract}
Fetal growth is compromised in animal models with high cortisol availability. In healthy pregnancies, the fetus is protected from high circulating cortisol levels by the placental $11 \beta$ hydroxysteroid dehydrogenase type $2(11 \beta$-HSD2), which is reduced in preeclampsia. We hypothesized increased placental cortisol availability in preeclampsia as missing link to fetal growth restriction and prematurity. Placental tissue was obtained from 39 pregnant women dichotomized normotensive $(n=16)$ or preeclamptic $(n=23)$. Placental steroid hormone metabolites were analyzed by gas chromatography-mass spectrometry. Apparent $11 \beta$-HSD2 enzyme activity was calculated as substrate to product ratio. Estradiol and pregnandiol positively correlated with gestational age. Cortisol was virtually absent in $93.8 \%$ of controls, yet detectable in $79.3 \%$ of preeclamptic samples resulting in an odds ratio (OR) of $0.019(95 \%$ CI 0.002-0.185) for the presence of placental cortisol. Apparent $11 \beta$-HSD2 activity directly correlated with birth weight $\left(R^{2}=0.16\right.$; $p<0.02)$ and gestational age $\left(R^{2}=0.11 ; p<0.04\right)$ ensuing a reduced risk of premature delivery (OR 0.12 ; 95\% CI 0.02-0.58). We conclude that normotensive pregnancies are characterized by an almost completely inactivated placental cortisol. In line with our hypothesis, reduced $11 \beta$-HSD2 activity in preeclampsia is unable to abolish placental cortisol, a finding clearly associated with prematurity and low birth weight. (Pediatr Res 65: 198-202, 2009)
\end{abstract}

$I^{n}$ pregnancy, high-free cortisol levels are prevalent within the maternal circulation. Glucocorticoids, such as cortisol and corticosterone, control fetal pre- and postnatal development by affecting multiple organ systems, evolving the term glucocorticoid programming (1). The placental $11 \beta$ hydroxysteroid dehydrogenase type $2(11 \beta$-HSD2) enzyme is up-regulated upon differentiation of cyto- into syncytiotrophoblasts and degrades high circulating maternal to appropriate fetal cortisol levels via conversion into its inactive metabolite cortisone (E) (2,3). The enzyme controls tissue cortisol availability and thus activation of the glucocorticoid receptor (4). If exogenous glucocorticoids are administered, or if cortisol degradation is affected by an $11 \beta$-HSD 2 activity genetically limited, birth weight is diminished $(5,6)$.

Received July 16, 2008; accepted September 2, 2008.

Correspondence: Markus G. Mohaupt, M.D., Division of Hypertension, Department of Nephrology/Hypertension, University Hospital Bern, 3010 Berne, Switzerland; e-mail: markus.mohaupt@insel.ch

Supported by departmental support, Swiss National Foundation for Scientific Research grants [Nr. 3200B0-113902/1 to (M.G.M.) and Nr. 3100A0-102153 to (B.M.F.)], and a German National Science Foundation grant [Nr. Ho1665/5-2 to (B.H.)].
Cell cultures exposed to hypoxia or to the plasma alterations of circulating molecules, whose levels are altered in preeclampsia, have demonstrated compromised 11 $\beta$-HSD2 mRNA, protein expression, and enzyme function (7-10). In preterm infants born small for gestation, the cord vein ratio of cortisol to cortisone and ex vivo enzyme assays indicated a reduced placental, yet also fetal $11 \beta$-HSD2 activity $(11,12)$. Similarly, placental $11 \beta$-HSD2 mRNA expression was found to be diminished in preeclampsia when compared with normal pregnancies $(2,13)$. If $11 \beta$-HSD2 activity is reduced, first, the placenta might transfer high cortisol levels into the fetal circulation, overwhelm its ability to degrade and to adjust cortisol to its current needs; and/or second, a high local cortisol concentration within the tissue could compromise placental functions and secondarily affect fetal development. The placenta is a gluco- and mineralocorticoid responsive tissue $(14,15)$. High tissue cortisol levels would unsuitably enable the transactivation of both receptor types, and thus potentially participate in the inappropriate placental phenotype of preeclampsia.

Given the indirect evidence in humans that an impaired placental degradation of cortisol via $11 \beta$-HSD2 is one of the molecular pathways leading to fetal programming, we present data collected in humans directly testing the missing link within the $11 \beta$-HSD2 hypothesis, the intraplacental cortisol concentration, using advanced highly sensitive techniques in a prospective case-control study in the tissue of interest (16). The purpose of the study was to test whether the proposed reduction of $11 \beta$ HSD2 activity in preeclampsia translates into high cortisol concentrations within placental tissue and whether a positive relationship exists to fetal growth restriction and prematurity.

\section{PATIENTS AND METHODS}

Patients. Tissue was obtained from placental samples of 39 pregnant women, who delivered by cesarean section, from the Department of Obstetrics of the University of Bern, Switzerland. Sixteen women were normotensive, whereby preterm deliveries were due to premature rupture of membranes, primary umbilical cord pathology, cervical insufficiency or uterine anomalies, and 23 were preeclamptic. Approval by the ethical review board of the University of Bern was given and informed consent was obtained from all women. Basic demographic data, including blood pressure, information on concurrent diseases and present medication were obtained.

The normotensive women (age $33.2 \pm 1.3 \mathrm{y}$ ) showed a systolic and diastolic blood pressure at admission for delivery of $117 \pm 9$ and $71 \pm 6 \mathrm{~mm}$

Abbreviation: 11 $\beta$-HSD2, $11 \beta$-hydroxysteroid dehydrogenase type 2 
$\mathrm{Hg}$, respectively, without proteinuria. Multiparous women had no history of complicated pregnancies, $53 \%$ were primiparous.

Preeclamptic individuals with preexisting arterial hypertension, diabetes mellitus, or renal disease were excluded from the study. Patients were included into the preeclamptic group if blood pressure was systolic $\geq 140 \mathrm{~mm}$ $\mathrm{Hg}(164 \pm 3 \mathrm{~mm} \mathrm{Hg})$ and diastolic $\geq 90 \mathrm{~mm} \mathrm{Hg}(96 \pm 3 \mathrm{~mm} \mathrm{Hg})$, and proteinuria was detectable $\geq 2+$ in dipstick or $>0.3 \mathrm{~g} / \mathrm{d}(4.94 \pm 1.13 \mathrm{~g} / \mathrm{d}$; $n=10)$ in the absence of urinary tract infection beyond the 20th wk of gestation (17). Of these complicated pregnancies, $9(39 \%)$ and $11(48 \%)$ were moderate and severe preeclamptic, respectively, and $3(13 \%)$ women with severe preeclampsia developed a superimposed syndrome of hemolysis, elevated liver enzymes, and low platelets. The gestational age of normotensive pregnant women was longer when compared with the preeclamptic pregnancies $(36.1 \pm 1.0$ versus $33.1 \pm 0.8 \mathrm{wk} ; p<0.02)$ and the birth weight was higher $(2683 \pm 296$ versus $1790 \pm 175 \mathrm{~g} ; p<0.009)$. Birth weight was adjusted for gestational age and expressed as percentage relative to German healthy newborns as determined separately for both sexes (normotensive and preeclamptic pregnancies $41.1 \pm 8.5$ versus $24.6 \pm 5.8$ percentile, respectively; $p=0.11$ ) (18). To control for the effects of gestational age on $11 \beta$-HSD2 activity and placental cortisol concentrations, preeclamptic and normotensive placentas were investigated from pregnancies of all gestational ages allowing survival of a newborn child.

Placenta tissue extraction. All placenta samples were taken immediately after Caesarean section. From a macroscopic normally appearing cotyledon, a biopsy measuring approximately $2 \times 2 \mathrm{~cm}$, including tissue from the basal to the chorionic plate, was taken, gently squeezed to remove blood, rinsed with ice-cold phosphate-buffered saline (PBS), gently squeezed to remove residual PBS, placed in precooled tubes, shock frozen in liquid nitrogen and stored at $-80^{\circ} \mathrm{C}$ until analysis (19). The tissue was minced and homogenized on ice; 0.4 to $1 \mathrm{~g}$ (wet weight) was used for steroid extraction.

Gas chromatography-mass spectrometry of steroid metabolites. Placental steroid metabolites were analyzed by gas chromatography-mass spectrometry using specifically designed programs for selective ion monitoring according to the method described by Shackleton (20).

The tissue was homogenized in $2 \mathrm{~mL}$ of water by ultrasonication (Branson Sonifier 250, Branson Ultrasonics, Danbury, CT). After adding $500 \mathrm{ng}$ of medroxyprogesterone (Steraloids, Newport, RI) as a recovery standard, the sample was extracted with $10 \mathrm{~mL}$ of methylenchloride (Merck, Darmstadt, Germany) on a rotator for $20 \mathrm{~min}$. After centrifugation at $3000 \mathrm{rpm}$ for $5 \mathrm{~min}$, the phases were separated and transferred into new tubes. The organic phase (containing the unconjugated steroids) was evaporated at $45^{\circ} \mathrm{C}$ under a stream of nitrogen. Stigmasterol (500 ng, Steraloids, Newport, RI) was added as a standard for derivatisation and chromatography. Subsequent to evaporation of the solvent, the samples were again derivatized by adding $100 \mu \mathrm{L}$ of methoxyamine- $\mathrm{HCl}$ (Pierce Biotechnology, Rockford, IL) in pyridine to form methyloximetrimethylsilyl ethers. The extracts were heated at $60^{\circ} \mathrm{C}$ for $1 \mathrm{~h}$. The solvent was evaporated under nitrogen at $60^{\circ} \mathrm{C}$ and $100 \mu \mathrm{L}$ of trimethylsilyl imidazole (Pierce Biotechnology, Rockford, IL) were included to form trimethylsilyl ethers. The derivatisation was carried out at $100^{\circ} \mathrm{C}$ for $16 \mathrm{~h}$. The derivatives were purified by gel filtration on Lipidx-5000 columns (Perkin Elmer, Wellesley, MA).

As a recovery standard, $500 \mathrm{ng}$ of medroxyprogesterone were supplemented to the water phase (containing the conjugated steroids). Proteins were precipitated with $5 \mathrm{~mL}$ of methanol (Merck, Darmstadt, Germany). After evaporation of the methanol at $60^{\circ} \mathrm{C}$ under nitrogen, the samples were adjusted to $2 \mathrm{~mL}$ using water. Conjugates were hydrolyzed with $15 \mathrm{mg}$ of sulfatase (Sigma Chemical, AG, Buchs, Switzerland) and $15 \mu \mathrm{L}$ of $\beta$-glucuronidase/arylsulfatase (Roche Diagnostics AG, Rotkreuz, Switzerland) in 0.1 $\mathrm{M}$ acetate buffer $\mathrm{pH} 4.6$ at $55^{\circ} \mathrm{C}$ for $3 \mathrm{~h}$. Deconjugated steroids were extracted from the hydrolysis mixture by solid phase extraction on Sep Pak C18 columns (Waters Corporation, Milford, MA). After the extraction, the columns were dried with nitrogen and the steroids were eluted with $4 \mathrm{~mL}$ of methanol. After adding $500 \mathrm{ng}$ of stigmasterol as a standard for derivatisation and chromatography, the samples were derivatized alike the unconjugated fraction. The derivatives were purified by gel filtration on Lipide-5000 columns.

Steroids were analyzed by gas chromatography-mass spectrometry and selective ion monitoring using a gas chromatograph $6890 \mathrm{~N}$ equipped with a mass selective detector 5973 N (Agilent Technologies, Palo Alto CA). One characteristic ion was programmed for each steroid analyzed. Chromatography was carried out during a temperature-programmed run over 35 min. A mixture containing known amounts of all steroids was analyzed on a regular basis for calibration. In each series, a standard sample was measured to control for reproducibility. The ratio of placental tissue steroids to placental wet weight was calculated.

To assess apparent enzyme activities as provided by the actual local hormone concentrations within the placental tissue, the following ratios were derived from the measured steroids:The activity of $11 \beta$-HSD2 in placental tissue was calculated from the ratio of (tetrahydrocortisol $+5 \alpha$-tetrahydrocortisol)/ tetrahydrocortisone and cortisol/cortisone, whereby high ratios indicate low en- zyme activity and low ratios indicate high. Tissue concentrations of steroid hormones were expressed in ng/g placental wet weight.

Statistical analysis. All data are presented as means \pm SEM. Power was calculated to detect the differences in $11 \beta$-HSD2 activity reported in preeclamptic and normal pregnancies (power $0.90 ; \alpha=0.05$ ) requiring a sample size of $n=16$ in each group (21). To test for statistically significant differences, $t$ test, the Mann-Whitney rank sum test, the Wilcoxon, or the Kruskal-Wallis test were applied. Linear regression analysis was performed for the continuous parameters [birth weight and gestational age as related to the ratio of (tetrahydrocortisol $+5 \alpha$-tetrahydrocortisol)/tetrahydrocortisone], and a logarithmic regression model was used to demonstrate the increase of estradiol and pregnandiol as related to gestational age. Standardized calculations of odds ratio (OR) and CIs were performed using log transformations and a normal approximation used for the CI. Significance was assigned at $p<0.05$ or at a constructed CI consisting of \pm the doubled $\ln$ SD of the OR. All statistical analyses were performed using SYSTAT Version 10 (SPSS, Chicago, IL).

\section{RESULTS}

Pregnancy-related steroid hormone metabolites. In total, we measured 41 steroid hormone metabolites by gas chromatography-mass spectrometry, including androgens, estrogens, progesterone, corticosterone, and cortisol. We included only those steroid hormones and their respective metabolites that were detected in more than $50 \%$ of the placentas of at least one patient group, as depicted in Table 1.

Estradiol and pregnandiol are considered to be relevant metabolites of the important steroid hormones, estradiol and progesterone, related to the maintenance of human pregnancy $(22,23)$. As expected, they clearly increase over time within the placenta (logarithmic correlation of pregnandiol and gestational age: $R^{2}=0.75, p<0.0001$ and $R^{2}=0.66, p<0.0001$ for normotensive and preeclamptic placentas, respectively; and estriol and gestational age: $R^{2}=0.78, p<0.0001$ and $R^{2}=0.77, p<0.0001$ for normotensive and preeclamptic placentas, respectively). No significant difference was observed between control and preeclamptic pregnancies with regard to pregnandiol and

Table 1. Steroid hormones, their respective metabolites and apparent $11 \beta$-HSD2 activity

\begin{tabular}{lrrl}
\hline \multicolumn{1}{c}{ Type of pregnancy } & Normotensive & Preeclamptic & \multicolumn{1}{c}{$P$} \\
\hline Corticosterone metabolites, [ng/g placenta] & & \\
Tetrahydrodehydrocorticosterone & $11.0 \pm 1.5$ & $17.2 \pm 2.4$ & 0.06 \\
Tetrahydrocorticosterone & $12.3 \pm 1.8$ & $15.5 \pm 1.9$ & 0.25 \\
5 $\alpha$-Tetrahydrocorticosterone & $10.9 \pm 1.5$ & $11.4 \pm 1.8$ & 0.86 \\
Cortisol metabolites, [ng/g placenta] & & & \\
Cortisone & $3.1 \pm 0.6$ & $3.3 \pm 0.7$ & 0.85 \\
Tetrahydrocortisone & $17.6 \pm 3.1$ & $14.8 \pm 3.5$ & 0.58 \\
$\alpha$-Cortolone & $15.0 \pm 4.1$ & $7.2 \pm 1.0$ & 0.04 \\
$\beta$-Cortolone & $6.0 \pm 1.1$ & $5.7 \pm 1.1$ & 0.87 \\
Cortisol & $0.0 \pm 0.0$ & $0.7 \pm 0.1$ & 0.0003 \\
Tetrahydrocortisol & $5.0 \pm 1.2$ & $5.2 \pm 0.8$ & 0.87 \\
5 $\alpha$-Tetrahydrocortisol & $4.1 \pm 1.0$ & $4.4 \pm 0.7$ & 0.79 \\
$\alpha$-Cortol & $4.6 \pm 1.2$ & $3.0 \pm 0.6$ & 0.19 \\
$\beta$-Cortol & $12.0 \pm 5.1$ & $7.8 \pm 0.5$ & 0.34 \\
Total cortisol metabolites & $67.4 \pm 14.7$ & $53.2 \pm 6.9$ & 0.34 \\
Androgen metabolites, [ng/g placenta] & & & \\
Androsterone & $16.9 \pm 9.5$ & $9.7 \pm 1.7$ & 0.39 \\
Androstenediol & $58.6 \pm 28.0$ & $27.7 \pm 2.6$ & 0.20 \\
Etiocholanolone & $1.0 \pm 0.2$ & $3.8 \pm 0.8$ & 0.007 \\
Apparent $11 \beta$-HSD2 activity & & & \\
(Tetrahydrocortisol + & $0.6 \pm 0.1$ & $0.9 \pm 0.1$ & 0.01 \\
$\quad 5 \alpha$-tetrahydrocortisol)/ & & & \\
tetrahydrocortisone & & & \\
Cortisol/cortisone & $0.0 \pm 0.0$ & $0.5 \pm 0.1$ & 0.002 \\
\hline
\end{tabular}



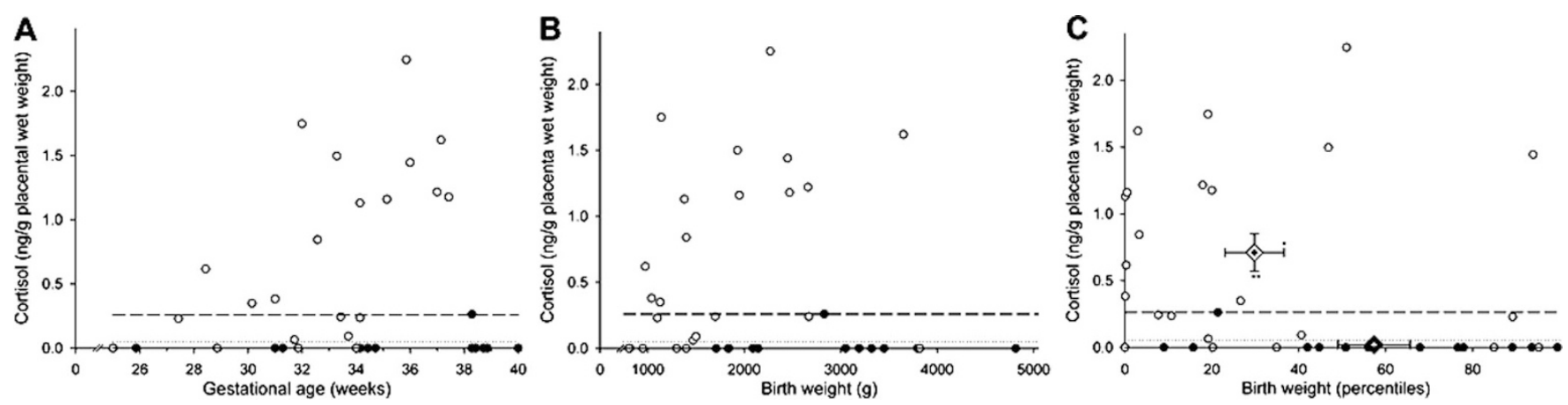

Figure 1. Cortisol concentrations of normotensive $(-)$ and preeclamptic $(O)$ are given as related $(A)$ to gestational age, $(B)$ to birth weight, and $(C)$ to relative birth weight percentiles. $\checkmark$ : the mean of controls. $\diamond:$ the mean of preeclamptic pregnancies. The upper limit of the $95 \%$ confidence interval of controls is given by a dotted line, the upper range limit of controls by a dashed line. $* p=0.017$ control versus preeclampsia, $* * p=0.0003$ control versus preeclampsia.

estradiol. No correlation was found for relative birth weight, blood pressure, birth length, and progesterone metabolites.

A statistically significant difference was found for etiocholanolone (Table 1).

Placental cortisol concentrations. In placentas of normotensive pregnancies, cortisol was virtually absent in $93.8 \%$ of the control cases studied irrespective of the gestational age (Table 1). In contrast, placental cortisol was detectable in most cases $(79.3 \%)$ of preeclampsia. This resulted in an OR of 0.019 (95\% CI $0.002-0.185$ ) of placental tissue to retain active cortisol in preeclampsia. Cortisol concentrations tended to increase with gestational age in placentas of preeclamptic pregnancies, yet this rise did not fit into a regression model (Fig. 1A). Higher birth weights, absolute (Fig. 1B) and relative to gestational age birth weight percentiles (Fig. 1C) were found with low tissue cortisol concentrations.

11ß-HSD activity in fetal placenta. The apparent $11 \beta$ HSD2 enzyme activity in the placenta was calculated by the ratio of placental (tetrahydrocortisol $+5 \alpha$-tetrahydrocortisol)/ tetrahydrocortisone and cortisol/cortisone (24). Both ratios were elevated, indicating a reduction of enzyme activity in preeclampsia (Table 1). The ratio of (tetrahydrocortisol + $5 \alpha$-tetrahydrocortisol)/tetrahydrocortisone directly correlated with birth weight $\left(R^{2}=0.16 ; p<0.02\right)$, indicating $11 \beta$-HSD enzyme activities are lowest with low birth weights (Fig. 2A). Similarly, $11 \beta$-HSD activity, as specified by a high ratio of cortisol/cortisone, was lowest in children with low birth weight (Fig. 2B). A higher apparent $11 \beta$-HSD2 enzyme activity was found in $71.4 \%$ of control pregnancies when compared with preeclamptic placentas if dichotomized by the linear regression analysis curve given by birth weight and (tetrahydrocortisol + $5 \alpha$-tetrahydrocortisol)/tetrahydrocortisone (Fig. 2A).

Apparent $11 \beta$-HSD2 enzyme activity showed a slight, yet consistent inverse correlation with gestational age $\left(R^{2}=0.11\right.$; $p<0.04$ ) as derived from the ratios of (tetrahydrocortisol + $5 \alpha$-tetrahydrocortisol)/tetrahydrocortisone (Fig. $3 A$ ). The ratio of cortisol/cortisone tended to be higher with a lower gestational age, representing a lower $11 \beta$-HSD enzyme activity (Fig. $3 B$ ). The likelihood of a premature delivery beyond the 34.1th wk of gestation, the mean of all pregnancies investigated in this study, is reduced in the presence of an above average $11 \beta$-HSD2 activity, as indicated by the linear regression in Figure $3 A$ (OR 0.12; 95\% CI 0.02-0.58).

\section{DISCUSSION}

Excess availability of glucocorticoids reduces fetal growth. Similarly, a reduced $11 \beta$-HSD2 activity is associated with a diminished weight at birth $(13,25,26)$. Low birth weight because of excess cortisol results in fetal programming of organ systems including cardiovascular and metabolic components

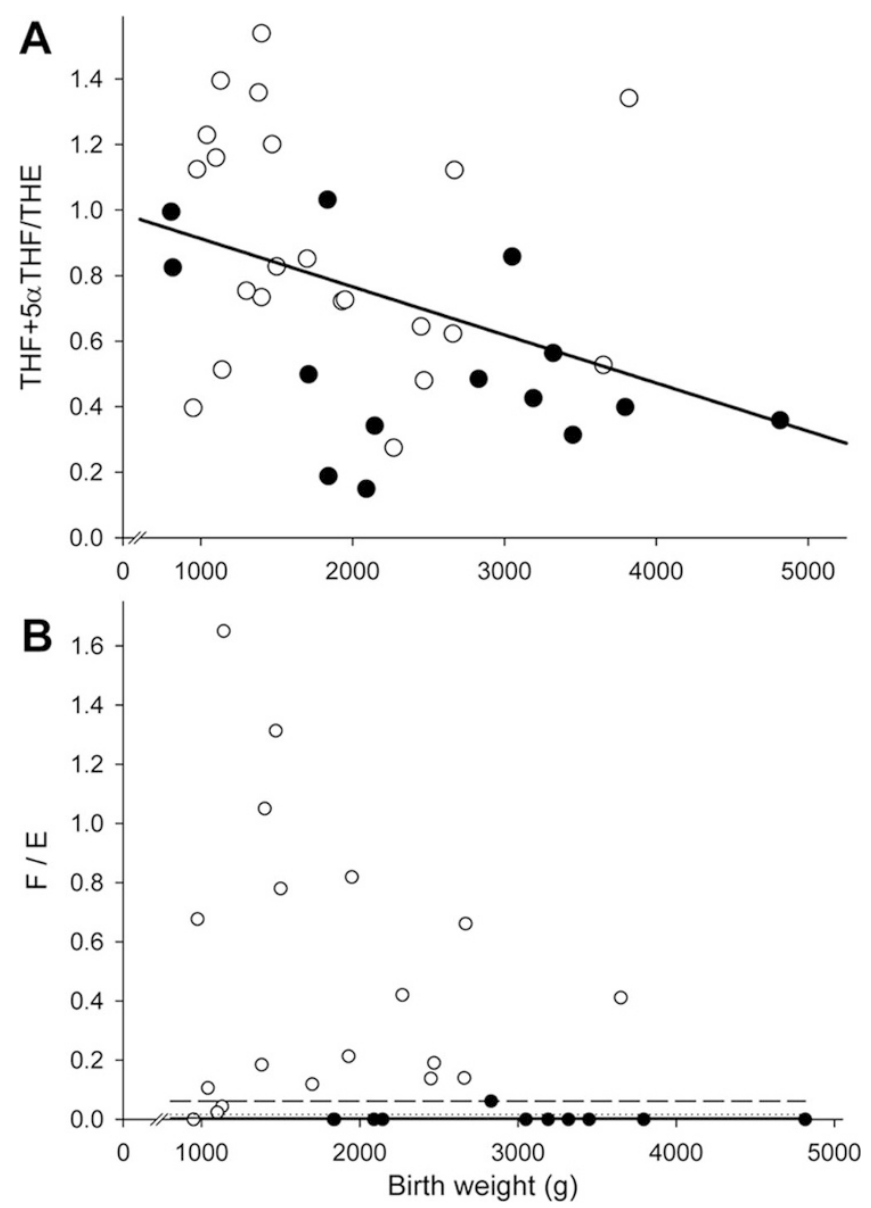

Figure 2. Apparent $11 \beta$-HSD2 activities were measured in placental tissue of normotensive $(O)$ and preeclamptic $(\bigcirc)$ pregnancies relative to birth weight and are depicted using either $(A)$ the (tetrahydrocortisol $+5 \alpha$-tetrahydrocortisol)/tetrahydrocortisone $((\mathrm{THF}+5 \alpha \mathrm{THF}) / \mathrm{THE})$ (linear regression $R^{2}=$ $0.16, p<0.02)$ or $(B)$ the cortisol/cortisone $(\mathrm{F} / \mathrm{E})$ ratio. The upper limit of the $95 \%$ confidence interval of controls is given by a dotted line, the upper range limit of controls by a dashed line. 


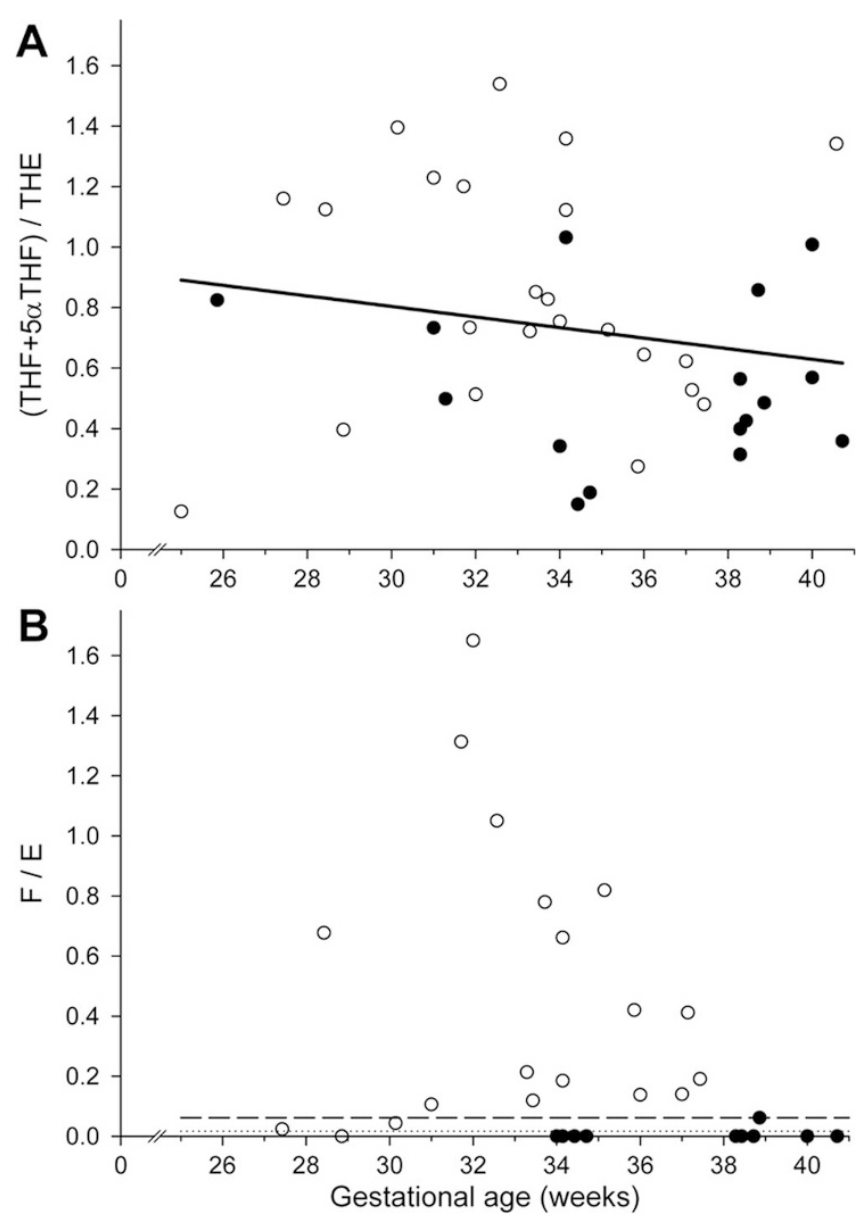

Figure 3. Apparent $11 \beta$-HSD2 activities were measured in placental tissue of normotensive $(\bigcirc)$ and preeclamptic $(\bigcirc)$ pregnancies relative to gestational age and are depicted as calculated using $(A)$ the (tetrahydrocortisol + $5 \alpha$-tetrahydrocortisol)/tetrahydrocortisone ((THF $+5 \alpha \mathrm{THF}) / \mathrm{THE})$ (linear regression $\left.R^{2}=0.11, p<0.04\right)$ and $(B)$ the cortisol/cortisone $(\mathrm{F} / \mathrm{E})$ ratio. The upper limit of the $95 \%$ confidence interval of controls is given by a dotted line, the upper range limit of controls by a dashed line.

[as reviewed by (1), including the kidneys (27)]. An association between reduced birth weight and the subsequent development of common cardiovascular and metabolic disorders has been observed (28-30). In intrauterine growth retardation or preeclampsia, several lines of evidence support the assumption that increased cortisol levels in fetal blood are found if a diminished $11 \beta$-HSD2 activity allows for more than $10-20 \%$ passage of maternal glucocorticoids (31-33). In the past, Walker et al.(34) additionally speculated about increased cortisol availability within placental tissue of preeclamptic pregnancies.

With our current results, we now provide the missing link: elevated cortisol availability within placental tissue if a pregnancy happens to be complicated by a preeclampsia. In contrast to preeclampsia, and in line with the assumption of a critical role of cortisol, the placental cortisol deactivation was very efficient in unaffected pregnancies, as confirmed in placentas of control patients where almost no cortisol was detectable. Increased cortisol availability involved nearly all placentas of women suffering from preeclampsia.

If placental cortisol levels are increased, the delivery of this active glucocorticoid to the fetus is likely to be augmented.
Yet, an influence of fetal cortisol levels still remains a matter of debate in newborns either small for gestational age or of preeclamptic pregnancies, which might in part be due to the high capacity of the fetus to regulate steroid hormone availability via degradation pathways $(12,35,36)$. Additional factors regulating cortisol action may still support a systemic fetal response, such as an increased glucocorticoid receptor expression that has been demonstrated in sheep or an attenuated fetal $11 \beta$-HSD2 activity $(12,37)$.

It is well conceivable that the placental $11 \beta$-HSD2 enzyme activity is diminished in preeclampsia because of signals present in this condition that have been demonstrated to reduce $11 \beta$-HSD2 activity in cultured trophoblasts, including hypoxia $(7,38-40)$. Similarly, it is obvious that a reduced deactivation of cortisol by $11 \beta$-HSD2 enzyme activity may have an enormous impact locally within the utero-placental unit. Numerous cells respond to an activation of the glucocorticoid receptor via an altered transcription of glucocorticoid responsive genes such as angiotensin II subtype 1 receptors (8). Accordingly, increased vasoconstriction could then lead to a reduced substrate and blood supply within the uteroplacental circulation and so compromise fetal growth and further worsen the placental inflammatory state. An important issue, with respect to increased local placental cortisol, is its potential to inhibit cyclin D3 and p27Kip1 as well as mitogen-activated protein kinase pathway (MAPK) signaling, which has recently been directly related to the glucocorticoid-induced leucine zipper. Inhibition of these pathways explains the antiproliferative capacity of cortisol. In support of this assumption, trophoblast invasion is shallow in preeclampsia, and a small placenta carries an increased risk of preeclampsia and reduced fetal growth.

Several investigators reported reduced birth weight in the presence of reduced tissue $11 \beta$-HSD2 enzyme activity, suggesting the importance of an appropriate level of $11 \beta$-HSD2 activity $(11,36)$. The present study clearly indicates a positive correlation of apparent $11 \beta$-HSD2 activity, as determined ex vivo from placental steroid hormones, with birth weight and length of gestation. Of interest, our data indicate that a preserved placental $11 \beta$-HSD2 activity reduced the risk of delivering a preeclamptic or premature pregnancy, conditions hindering a beneficial fetal outcome. Although controversial in the literature, our own observations do not support a role of an altered placental $11 \beta$-HSD1 enzyme activity (data not shown), which could potentially restore active cortisol $(21,41)$.

Because $11 \beta$-HSD2 activity varies by only $8 \%$ between different areas of the human placenta, erroneous sampling is unlikely (26). The detection of increasing concentrations of estradiol and progesterone metabolites with gestational age is an additional support to the assumption of correct sampling. As recently confirmed by others, these steroid hormones did not differ between normotensive and preeclamptic pregnancies (42). The limitation of any human study with respect to the impact of placental cortisol availability in prepartal stages of normal or pathologic pregnancies is an issue that might be worth addressing in animal models. We were unable to correlate the apparent $11 \beta$-HSD2 activity to maternal blood pressure. This observation is in line with the absence of elevated cortisol in the maternal circulation in preeclampsia. Furthermore, in the pres- 
ence of a reduced circulating plasma volume in preeclampsia, the hypothesis of a cortisol-dependent mineralocorticoid-like effect promoting sodium and water reabsorption within the distal nephron of the maternal kidney is unlikely.

Male fetal gender was evenly distributed among the pregnancy outcomes, yet the androgen metabolite etiocholanolone was increased in preeclampsia. Etiocholanolone appears to be largely unaffected by pregnancy. However, like antenatal detection of elevated urinary $16 \alpha$-hydroxydehydroepiandrosterone concentrations, reduced placental sulfatase activity during preeclampsia might well elevate measured placental etiocholanolone levels (43). It is currently unknown whether placental steroid sulfatase activity is reduced because of preeclampsia.

In conclusion, normotensive pregnancies are characterized by an $11 \beta$-HSD2 activity sufficient to almost completely inactivate cortisol within the placenta. In contrast, reduced $11 \beta$-HSD2 activity in preeclampsia is unable to abolish placental cortisol, a finding clearly associated with prematurity and low birth weight. Future studies need to clearly address the impact of locally elevated cortisol concentrations on hemodynamic and structural changes within placental tissue and the impact of modulators of $11 \beta$-HSD2 enzyme activity. Clinical studies tailored to improve preeclampsia should address placental $11 \beta$-HSD2 activity and cortisol availability as factors affecting fetal growth.

\section{REFERENCES}

1. Seckl JR, Holmes MC 2007 Mechanisms of disease: glucocorticoids, their placental metabolism and fetal 'programming' of adult pathophysiology. Nat Clin Pract Endocrinol Metab 3:479-488

2. Schoof E, Girstl M, Frobenius W, Kirschbaum M, Repp R, Knerr I, Rascher W, Dotsch J 2001 Course of placental $11 \beta$-hydroxysteroid dehydrogenase type 2 and 15-hydroxyprostaglandin dehydrogenase mRNA expression during human gestation. Eur J Endocrinol 145:187-192

3. Hardy DB, Yang K 2002 The expression of $11 \beta$-hydroxysteroid dehydrogenase type 2 is induced during trophoblast differentiation: effects of hypoxia. J Clin Endocrinol Metab 87:3696-3701

4. Odermatt A, Arnold P, Frey FJ 2001 The intracellular localization of the mineralocorticoid receptor is regulated by $11 \beta$-hydroxysteroid dehydrogenase type 2 . J Biol Chem 276:28484-28492

5. French NP, Hagan R, Evans SF, Godfrey M, Newnham JP 1999 Repeated antenatal corticosteroids: size at birth and subsequent development. Am J Obstet Gynecol 180:114-121

6. Reinisch JM, Simon NG, Karow WG, Gandelman R 1978 Prenatal exposure to prednisone in humans and animals retards intrauterine growth. Science 202:436-438

7. Heiniger CD, Kostadinova RM, Rochat MK, Serra A, Ferrari P, Dick B, Frey BM, Frey FJ 2003 Hypoxia causes down-regulation of $11 \beta$-hydroxysteroid dehydrogenase type 2 by induction of Egr-1. FASEB J 17:917-919

8. Lanz B, Kadereit B, Ernst S, Shojaati K, Causevic M, Frey BM, Frey FJ, Mohaupt MG 2003 Angiotensin II regulates $11 \beta$-hydroxysteroid dehydrogenase type 2 via AT2 receptors. Kidney Int 64:970-977

9. Lanz CB, Causevic M, Heiniger C, Frey FJ, Frey BM, Mohaupt MG 2001 Fluid shear stress reduces $11 \beta$-hydroxysteroid dehydrogenase type 2 . Hypertension 37:160-169

10. Kossintseva I, Wong S, Johnstone E, Guilbert L, Olson DM, Mitchell BF 2006 Proinflammatory cytokines inhibit human placental $11 \beta$-hydroxysteroid dehydrogenase type 2 activity through $\mathrm{Ca}^{2+}$ and cAMP pathways. Am J Physiol Endocrinol Metab 290:E282-E288

11. Kajantie E, Dunkel L, Turpeinen U, Stenman UH, Wood PJ, Nuutila M, Andersson S 2003 Placental 11 $\beta$-hydroxysteroid dehydrogenase-2 and fetal cortisol/cortisone shuttle in small preterm infants. J Clin Endocrinol Metab 88:493-500

12. Dy J, Guan H, Sampath-Kumar R, Richardson BS, Yang K 2008 Placental $11 \beta$ hydroxysteroid dehydrogenase type 2 is reduced in pregnancies complicated with idiopathic intrauterine growth restriction: evidence that this is associated with an attenuated ratio of cortisone to cortisol in the umbilical artery. Placenta 29:193-200

13. McCalla CO, Nacharaju VL, Muneyyirci-Delale O, Glasgow S, Feldman JG 1998 Placental $11 \beta$-hydroxysteroid dehydrogenase activity in normotensive and preeclamptic pregnancies. Steroids 63:511-515

14. Lee MJ, Wang Z, Yee H, Ma Y, Swenson N, Yang L, Kadner SS, Baergen RN, Logan SK, Garabedian MJ, Guller S 2005 Expression and regulation of glucocorticoid receptor in human placental villous fibroblasts. Endocrinology 146:4619-4626

15. Driver PM, Rauz S, Walker EA, Hewison M, Kilby MD, Stewart PM 2003 Characterization of human trophoblasts as a mineralocorticoid target tissue. Mol Hum Reprod 9:793-798
16. Seckl JR, Cleasby M, Nyirenda MJ 2000 Glucocorticoids, $11 \beta$-hydroxysteroid dehydrogenase, and fetal programming. Kidney Int 57:1412-1417

17. Higgins JR, de Swiet M 2001 Blood-pressure measurement and classification in pregnancy. Lancet 357:131-135

18. Voigt M, Schneider KT, Jahrig K 1996 [Analysis of 1992 birth sample in Germany. 1: new percentile values of the body weight of newborn infants]. Geburtshilfe Frauenheilkd 56:550-558

19. Beinder E, Mohaupt MG, Schlembach D, Fischer T, Sterzel RB, Lang N, Baylis C 1999 Nitric oxide synthase activity and Doppler parameters in the fetoplacental and uteroplacental circulation in preeclampsia. Hypertens Pregnancy 18:115-127

20. Shackleton CH 1993 Mass spectrometry in the diagnosis of steroid-related disorders and in hypertension research. J Steroid Biochem Mol Biol 45:127-140

21. Alfaidy N, Gupta S, DeMarco C, Caniggia I, Challis JR 2002 Oxygen regulation of placental $11 \beta$-hydroxysteroid dehydrogenase 2: physiological and pathological implications. J Clin Endocrinol Metab 87:4797-4805

22. Gunter HH, Berger L, Messner U, Niesert S 1995 [Estriol and human placental lactogen as risk indicators in pregnancies of diabetic and hypertensive patients]. $\mathrm{Z}$ Geburtshilfe Neonatol 199:142-147

23. Oszczygiel VA 1975 [Progesterone and pregnandiol levels in the pripheral blood and urinary pregnandiol level in pregnant women before and after delivery]. Zentralbl Gynakol 97:301-306

24. Best R, Walker BR 1997 Additional value of measurement of urinary cortisone and unconjugated cortisol metabolites in assessing the activity of $11 \beta$-hydroxysteroid dehydrogenase in vivo. Clin Endocrinol (Oxf) 47:231-236

25. Kitanaka S, Tanae A, Hibi I 1996 Apparent mineralocorticoid excess due to $11 \beta$-hydroxysteroid dehydrogenase deficiency: a possible cause of intrauterine growth retardation. Clin Endocrinol (Oxf) 44:353-359

26. Stewart PM, Rogerson FM, Mason JI 1995 Type $211 \beta$-hydroxysteroid dehydrogenase messenger ribonucleic acid and activity in human placenta and fetal membranes: its relationship to birth weight and putative role in fetal adrenal steroidogenesis. J Clin Endocrinol Metab 80:885-890

27. Symonds ME, Stephenson T, Gardner DS, Budge H 2007 Long-term effects of nutritional programming of the embryo and fetus: mechanisms and critical windows. Reprod Fertil Dev 19:53-63

28. Rich-Edwards JW, Kleinman K, Michels KB, Stampfer MJ, Manson JE, Rexrode KM, Hibert EN, Willett WC 2005 Longitudinal study of birth weight and adult body mass index in predicting risk of coronary heart disease and stroke in women. BMJ 330: 1115

29. Curhan GC, Chertow GM, Willett WC, Spiegelman D, Colditz GA, Manson JE, Speizer FE, Stampfer MJ 1996 Birth weight and adult hypertension and obesity in women. Circulation 94:1310-1315

30. Barker DJ, Gluckman PD, Godfrey KM, Harding JE, Owens JA, Robinson JS 1993 Fetal nutrition and cardiovascular disease in adult life. Lancet 341:938-941

31. Benediktsson R, Calder AA, Edwards CR, Seckl JR 1997 Placental $11 \beta$ hydroxysteroid dehydrogenase: a key regulator of fetal glucocorticoid exposure. Clin Endocrinol (Oxf) 46:161-166

32. Goland RS, Jozak S, Warren WB, Conwell IM, Stark RI, Tropper PJ 1993 Elevated levels of umbilical cord plasma corticotropin-releasing hormone in growth-retarded fetuses. J Clin Endocrinol Metab 77:1174-1179

33. Goland RS, Tropper PJ, Warren WB, Stark RI, Jozak SM, Conwell IM 1995 Concentrations of corticotrophin-releasing hormone in the umbilical-cord blood of pregnancies complicated by pre-eclampsia. Reprod Fertil Dev 7:1227-1230

34. Walker BR, Williamson PM, Brown MA, Honour JW, Edwards CR, Whitworth JA $199511 \beta$-Hydroxysteroid dehydrogenase and its inhibitors in hypertensive pregnancy. Hypertension 25:626-630

35. Strinic T, Bukovic D, Radic A, Sumilin L, Hauptman D, Sovic T 2005 Comparison of fetal plasma cortisol level between eutrophic and hypotrophic newborns. Coll Antropol 29:739-741

36. Procianoy RS, Cecin SK 1986 Umbilical cord dehydroepiandrosterone sulfate and cortisol levels in preterm infants born to pre-eclamptic mothers. Acta Paediatr Scand 75:279-282

37. Matthews SG, Yang K, Challis JR 1995 Changes in glucocorticoid receptor mRNA in the developing ovine pituitary and the effects of exogenous cortisol. J Endocrinol 144:483-490

38. Kadereit B, Fustier P, Shojaati K, Frey BM, Frey FJ, Mohaupt MG 2005 Extracellular ATP determines $11 \beta$-hydroxysteroid dehydrogenase type 2 activity via purinergic receptors. J Am Soc Nephrol 16:3507-3516

39. Heiniger CD, Rochat MK, Frey FJ, Frey BM 2001 TNF- $\alpha$ enhances intracellular glucocorticoid availability. FEBS Lett 507:351-356

40. Homan A, Guan H, Hardy DB, Gratton RJ, Yang K 2006 Hypoxia blocks $11 \beta$ hydroxysteroid dehydrogenase type 2 induction in human trophoblast cells during differentiation by a time-dependent mechanism that involves both translation and transcription. Placenta 27:832-840

41. Struwe E, Berzl GM, Schild RL, Beckmann MW, Dorr HG, Rascher W, Dotsch J 2007 Simultaneously reduced gene expression of cortisol-activating and cortisolinactivating enzymes in placentas of small-for-gestational-age neonates. Am J Obstet Gynecol 197:43.e1-e6

42. Salas SP, Marshall G, Gutierrez BL, Rosso P 2006 Time course of maternal plasma volume and hormonal changes in women with preeclampsia or fetal growth restriction. Hypertension 47:203-208

43. Glass IA, Lam RC, Chang T, Roitman E, Shapiro LJ, Shackleton CH 1998 Steroid sulphatase deficiency is the major cause of extremely low oestriol production at mid-pregnancy: a urinary steroid assay for the discrimination of steroid sulphatase deficiency from other causes. Prenat Diagn 18:789-800 